\title{
Polymorphisms in microRNA targets: a source of new molecular markers for male reproduction
}

\author{
Jernej Ogorevc, Peter Dovc and Tanja Kunej \\ Asian Journal of Andrology (2011) 13, 505-508; doi:10.1038/aja.2011.4; published online 11 April 2011
}

\section{Dear Editor,}

Herein we discuss the impact of microRNA (miRNA) target genetic variability in male infertility genes, which can represent a source of novel molecular-genetic markers that can be used for the diagnosis of male infertility. Male-factor infertility accounts for 30\%-40\% of infertility cases. The causes of spermatogenetic failure found in most cases of non-obstructive azoospermia or severe oligozoospermia still remain idiopathic. $^{1}$

Significant progress has recently been made by utilizing small RNAs, e.g., small interfering RNAs, miRNAs and piwi-interacting RNAs, to elucidate the molecular mechanisms that regulate spermatogenesis. ${ }^{2}$ The miRNAs repress protein synthesis from targeted messenger RNAs (mRNAs) and control approximately $30 \%$ of human genes. ${ }^{3}$ Single-nucleotide polymorphisms (SNPs) of miRNA precursors and their target sites, as well as the silencing machinery, interfere with miRNA function and are likely to affect phenotypic variation, including disease susceptibility. ${ }^{4}$ The term miR-SNP refers to the variation that occurs in the miRNA gene sequence, whereas miR-TS-SNP refers to the SNP within the miRNA target site (TS) or binding site. ${ }^{5}$ miR-TS-SNPs have been associated with many diseases, including tumour susceptibility; ${ }^{6}$ however, mir-TS-SNPs have not yet been shown to affect male fertility.

The aim of this study was to explore in silico genetic variability of $3^{\prime}$ UTR miRNA target sites of the selected (in)fertility related candidate genes to determine whether miR-TS-SNPs could represent a starting point for the discovery of novel genetic markers that affect male fertility phenotypes via miRNA regulation. This analysis was performed on the 34 candidate genes associated with this trait most frequently. ${ }^{7}$

Using online tools, the selected candidate human and mouse orthologs were analyzed for the following: (i) testicular expression levels obtained using BioGPS (Genomic Institute of the Novartis Research Foundation; GNF) (http://biogps.gnf.org/); (ii) conserved miRNA target sites using TargetScan (http://www.targetscan.org/); and (iii) polymorphic miRNA target sites using Patrocles (http://www.patrocles.org/).

The results of the analyses are presented in Table 1 . TargetScan, which predicts biological targets of miRNAs by searching for the presence of conserved sites across several species that match the miRNAs seed regions, revealed that more than two-thirds of the analyzed candidate genes in human $(76 \% ; 26 / 34)$ and mouse $(68 \% ; 23 / 34)$ genomes comprise conserved miRNA-binding sites. Candidate genes were further analyzed for miR-TS-SNPs within the 3'-UTRs of human and mouse orthologs using Patrocles. The search revealed 55 and 33 miR-TS-SNPs in humans and mice, respectively. More than half $(62 \% ; 21 / 34)$ of the analyzed human candidate genes contained miR-TS-SNPs; the most polymorphic were KIT ligand (KITL, $12 \mathrm{SNPs}$ ), actin beta (ACTB, 5 SNPs), angiotensin I converting enzyme (peptidyl-dipeptidase A) 1 (ACE, 4 SNPs), calcium/calmodulin-dependent protein kinase IV (CAMK4, 4 SNPs), oestrogen receptor 1 (ESR1, 4 SNPs) and 5,10methylenetetrahydrofolate reductase (MTHFR, 4 SNPs) (Table 1). For example, the highly polymorphic 3'-UTR of KITL spans a region of only $3740 \mathrm{bp}$; therefore, sequencing such a region could be highly informative in the context of discovering novel genetic markers. In mice, nearly half $(41 \% ; 14 / 34)$ of the genes contained miR-TS-SNP; the most polymorphic were prolactin receptor ( $P R L R, 7 \mathrm{SNPs})$, oestrogen receptor 1 (ESR1, 6 SNPs) and KIT ligand (KITL, 5 SNPs). Despite the known problem of a low overlap between the target prediction tools, TargetScan and Patrocles predicted several overlapping miRNA-target pairs: AKT1 (miR-25 and miR-32), DAZL (miR-1269), ESR1 (miR-211 and miR204) and RAD23A (miR-361-5p). However, predicted miRNA-mRNA pairs described in the present study have not been experimentally validated thus far, and the validation status of several SNPs is still unknown.

Furthermore, predicted miR-TS-SNPs and conserved target sites were compared to an miRNA expression study performed in nonobstructive azoospermic patients and compared to fertile controls. ${ }^{8}$ Notably, it was possible to determine infertility-related miRNA-target pairs; Patrocles revealed miR-TS-SNPs in the analyzed candidates that are targeted by miRNAs previously reported as being either up- or downregulated in azoospermic patients. There were miR-TS-SNPs for three upregulated miRNAs, miR-129-5p (having predicted polymorphic target site in DAZL), miR-302a (ESR1) and miR-557 (PRM2), as well as for 10 downregulated miRNAs, mir-31* (ACE), miR-32 (AKT1), miR-199b-5p (APRT), miR-153, miR-425, miR-448 (all in CREM), miR-515-5p (KITL), miR-363* (MTHFR), miR-31 (PRM1) and miR-374a* (RAD23A). Additionally, TargetScan predicted conserved target sites in human orthologs of infertility candidate genes for three upregulated miRNAs, miR-302a (predicted target in AKT1), miR-129-5p (CAMK4) and miR-557 (DAZL), as well as for 14 downregulated miRNAs, miR-145 (ACTB), miR-302d, miR-372, miR-373 (all in AKT1), miR-301b and miR-454 (both in AR), miR-1 (CREM), miR-548a-3p (DAZ-family), miR-548c-3p (DAZ-family and

Department of Animal Science, Biotechnical Faculty, University of Ljubljana, Domzale 1230, Slovenia 
Table 1 Selected genes associated with a male reproduction phenotype: level of expression in testes, conserved target site analysis and polymorphisms at miRNA target sites ${ }^{a}$




Table 1 (Continued) Selected genes associated with a male reproduction phenotype: level of expression in testes, conserved target site analysis and polymorphisms at miRNA target sites ${ }^{a}$

\begin{tabular}{|c|c|c|c|c|c|c|c|}
\hline \multirow[t]{3}{*}{ Gene } & \multirow{3}{*}{$\begin{array}{l}\text { GNF BioGPS } \\
\text { Expression in } \\
\text { testis (mouse/ } \\
\text { human) }\end{array}$} & \multicolumn{2}{|c|}{ TargetScan analysis } & \multicolumn{4}{|c|}{ Patrocles analysis } \\
\hline & & \multirow{2}{*}{$\begin{array}{l}\text { No. of conserved } \\
\text { (poorly conserved) } \\
\text { miRNA target sites } \\
\text { in mouse/human }\end{array}$} & \multirow{2}{*}{$\begin{array}{l}\text { miRNAs binding to } \\
\text { conserved octamers }^{b}\end{array}$} & \multirow{2}{*}{$\begin{array}{l}\text { No. of SNPs in } \\
\text { miRNA target } \\
\text { sites (mouse/ } \\
\text { human) }\end{array}$} & \multirow{2}{*}{$\begin{array}{l}\text { miRNAs binding } \\
\text { to polymorphic } \\
\text { target sites }\end{array}$} & \multicolumn{2}{|c|}{ NCBI or ENSEMBL SNP ID } \\
\hline & & & & & & Mouse & Human \\
\hline $\begin{array}{l}K I T L \\
\quad(K I T L G)\end{array}$ & $+/+$ & $2 / 2(0 / 4)$ & $\begin{array}{l}\text { mmu-miR-: 27a, 27b } \\
\text { hsa-miR-: 132, } 212\end{array}$ & $5 / 12$ & $\begin{array}{l}\text { mmu-miR-: 103, } \\
\text { 107, 485, } 881^{*} \\
\text { 671-5p } \\
\text { hsa-miR-: 496, } \\
\text { 921, 620, 1270, } \\
\text { 299-5p, 586, } \\
\text { 515-5p, 519e*, } \\
\text { 335*, 618, } 203\end{array}$ & $\begin{array}{l}\text { rs51068821 } \\
\text { rs51436505 } \\
\text { rs51005420 } \\
\text { rs47027334 } \\
\text { rs46343331 }\end{array}$ & $\begin{array}{l}\text { rs12344 } \\
\text { rs3203697 } \\
\text { rs41311951 } \\
\text { rs41307009 } \\
\text { rs41309421 } \\
\text { rs41307046 } \\
\text { rs41300052 } \\
\text { rs4842625 } \\
\text { rs35072453 } \\
\text { rs41306433 } \\
\text { rs41300048 } \\
\text { rs995030 }\end{array}$ \\
\hline$\angle H B$ & $+/+$ & $1 / 1(4 / 6)$ & $\begin{array}{l}\text { mmu-miR-325 } \\
\text { hsa-miR-1300 }\end{array}$ & $0 / 0$ & - & - & - \\
\hline MTHFR & $++/+$ & $1 / 1(0 / 4)$ & miR-22 & $0 / 4$ & $\begin{array}{l}\text { hsa-miR-: } 363^{*}, \\
1228^{*}\end{array}$ & - & $\begin{array}{l}\text { rs35134728 } \\
\text { rs34762557 } \\
\text { rs3737966 } \\
\text { ENSSNP11488330 }\end{array}$ \\
\hline$P O L G$ & $++/+$ & 0/0 (16/23) & & $0 / 0$ & - & - & - \\
\hline PRDM9 & $++/+$ & NA & NA & $0 / 0$ & - & - & - \\
\hline$P R L R$ & $++/+$ & $1 / 1(1 / 1)$ & miR-142-3p & $7 / 0$ & $\begin{array}{c}\text { mmu-miR-: 205, } \\
\text { 207, 26b*, 29a, } \\
\text { 29b, 29c, 743a, } \\
\text { 743-b-3p, } 374\end{array}$ & $\begin{array}{l}\text { rs32240442 } \\
\text { rs47952152 } \\
\text { rs45986226 } \\
\text { rs46045208 } \\
\text { rs46505738 } \\
\text { rs49089943 } \\
\text { rs32350023 }\end{array}$ & - \\
\hline PRM1 & $+++/+++$ & $3 / 3(3 / 9)$ & $\begin{array}{l}\text { miR-484 } \\
\text { mmu-miR-: 669g, } 325 \\
\text { hsa-miR-: 1256, } 1305\end{array}$ & $0 / 1$ & hsa-miR-31 & - & rs11544791 \\
\hline PRM2 & $+++/+++$ & 0/1 (11/14) & hsa-miR-1266 & $0 / 1$ & hsa-miR-: 507, 557 & - & rs1042801 \\
\hline$R A D 23 A$ & $+/++$ & $3 / 11(26 / 41)$ & $\begin{array}{l}\text { miR-423-5p } \\
\text { mmu-miR-: 703, } 361 \\
\text { hsa-miR-: 548a-3p, 548e-3p, } \\
\text { 548f-3p, 1302, 361-5p, } \\
\text { 548o, 1323, 548e, 548f }\end{array}$ & $2 / 2$ & $\begin{array}{l}\text { mmu-miR-665 } \\
\text { hsa-miR-: 29a-2*, } \\
\text { 374a*, 361-5p }\end{array}$ & $\begin{array}{l}\text { rs33102324 } \\
\text { rs13470179 }\end{array}$ & $\begin{array}{l}\text { rs41558417 } \\
\text { rs1059298 }\end{array}$ \\
\hline$R B P 4$ & $-1-$ & $1 / 1(10 / 13)$ & $\begin{array}{l}\text { mmu-miR-466I } \\
\text { hsa-miR-577 }\end{array}$ & $0 / 0$ & - & - & - \\
\hline SYCP3 & $++/++$ & $2 / 0(10 / 13)$ & mmu-miR-: 409-3p, 325 & $0 / 0$ & - & - & - \\
\hline TNP1 & $+++/+++$ & $4 / 4(0 / 0)$ & miR-: 181a, 181b, 181c, 181d & $1 / 0$ & mmu-miR-434-5p & rs3022818 & - \\
\hline TNP2 & $+++/+++$ & $1 / 0(1 / 6)$ & mmu-miR-153 & $0 / 0$ & - & - & - \\
\hline$\cup B E 2 B$ & $+/++$ & $1 / 2(0 / 9)$ & $\begin{array}{l}\text { miR-124 } \\
\text { hsa-miR-506 }\end{array}$ & $0 / 2$ & $\begin{array}{l}\text { hsa-let-7c }{ }^{*} \\
\text { hsa-miR-424 }\end{array}$ & - & $\begin{array}{l}\text { rs36072121 } \\
\text { rs11538104 }\end{array}$ \\
\hline
\end{tabular}

Abbreviation: microRNA, miRNA.

${ }^{a}$ Human miRNAs highlighted in bold were experimentally confirmed to be up- or downregulated in patients with non-obstructive azoospermia. ${ }^{8}$

${ }^{\mathrm{b}}$ Mouse and human unless specifically specified.

${ }^{c} D A Z$ gene family contains genes $D A Z 1, D A Z 2, D A Z 3$ and $D A Z 4 ;+$, below median; ++ , median-10 $\times$ median; +++ , above $10 \times$ median; NA, data not available.

* Product from the opposite arm of the miRNA precursor.

DAZL), miR-590-3p (DAZL), miR-651 (GNRHR), miR-548a-3p (RAD23A), and mir-181a and miR-181d (both in TNP1).

Genes with high levels of testis-specific expression, polymorphic $3^{\prime}$ UTRs, and/or conserved miRNA target sites represent promising candidates for targets involved in miRNA-regulated pathogenesis of male infertility. Future analyses can now be directed toward sequencing the $3^{\prime}$-UTRs of the suggested candidate genes and identifying the genetic variability underlying miRNA regulation. However, the prediction and validation of such miRNA target genes represents a critical step, especially because there is no agreement about the experimental procedures that should be followed to demonstrate miRNA-mRNA interactions. ${ }^{9}$ For example, negatively correlated coexpression of mRNA-miRNA pairs may indicate possible interactions; therefore, differential transcriptomic analyses of candidate genes and their putative miRNA target pairs in testes could be the first step in identifying such pairs. Putative miRNA-mRNA pairs can now be further experimentally confirmed, 
and miR-TS-SNPs can be validated and analyzed for the effect of a gain or loss of miRNA binding sites. Our results imply that miR-TS-SNPs and miR-SNPs, in combination with expression patterns of miRNA-targeted genes, could influence the post-transcriptional regulation of fertilityassociated genes and therefore contribute to male fertility problems.

In our opinion, this miRNA-related literature and database integration could be beneficial for researchers studying the involvement of miRNAs in male fertility and could present a starting point for the development of novel male infertility-associated genetic markers.

\section{AUTHOR CONTRIBUTIONS}

JO performed database searches and extracted information from publications. He participated in data analysis and draft writing. TK initiated and coordinated the project, supervised data collection and participated in data analysis and draft writing. PD participated in draft writing and final editing of the text. He is also mentor of JO and PI in the research programme from which the project was supported.

\section{COMPETING FINANCIAL INTERESTS}

The authors disclose any financial and personal relationships with third persons or organizations that could inapproproately bias or influence their research work.

\section{ACKNOWLEDGMENTS}

This work was supported by the Slovenian Research Agency, through the Comparative Genomics and Genome Biodiversity research program (P4-0220).

1 Nuti F, Krausz C. Gene polymorphisms/mutations relevant to abnormal spermatogenesis. Reprod Biomed Online 2008; 16: 504-13.

2 He ZP, Kokkinaki M, Pant D, Gallicano GI, Dym M. Small RNA molecules in the regulation of spermatogenesis. Reproduction 2009; 137: 901-11.

3 Lewis BP, Burge CB, Bartel DP. Conserved seed pairing, often flanked by adenosines, indicates that thousands of human genes are microRNA targets. Cell 2005; 120: 1520.

4 Georges M, Coppieters W, Charlier C. Polymorphic miRNA-mediated gene regulation: contribution to phenotypic variation and disease. Curr Opin Genet Dev 2007; 17: 166-76.

5 Sun GH, Yan J, Noltner K, Feng JN, Li HT et al. SNPs in human miRNA genes affect biogenesis and function. RNA 2009; 15: 1640-51.

6 Nicoloso MS, Sun H, Spizzo R, Kim H, Wickramasinghe P et al. Single-nucleotide polymorphisms inside microRNA target sites influence tumor susceptibility. Cancer Res 2010; 70: 2789-98.

7 Ogorevc J, Dovc P, Kunej T. Comparative genomics approach to identify candidate genetic loci for male fertility. Reprod Domest Anim 2011; 46: 229-39.

8 Lian J, Zhang XS, Tian H, Liang N, Wang Y et al. Altered microRNA expression in patients with non-obstructive azoospermia. Reprod Biol Endocrinol 2009; 7: 13.

9 Kuhn DE, Martin MM, Feldman DS, Terry AV, Nuovo GJ et al. Experimental validation of miRNA targets. Methods 2008; 44: 47-54. 